\title{
The McDonaldization of Academic Libraries?
}

\section{Brian Quinn}

\begin{abstract}
George Ritzer, a sociologist at the University of Maryland, has proposed an influential thesis that suggests that many aspects of the fast food industry are making their way into other areas of society. This article explores whether his thesis, known as the McDonaldization thesis, is applicable to academic libraries. Specifically, it seeks to determine to what extent academic libraries may be considered McDonaldized, and if so, what effect McDonaldization may be having on them. It also investigates some possible alternatives to McDonaldization, and their implications for academic libraries.
\end{abstract}

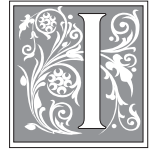

n 1993, George Ritzer, a sociologist at the University of Maryland, wrote a book titled The McDonaldization of Society. ${ }^{1}$

It caused considerable controversy in the field of sociology and in academia generally, sold many copies, and inspired several articles and even a book to be written about the subject. ${ }^{2}$ In his book, Ritzer argued that the principles of the fast-food industry had gradually come to pervade other areas of society.

In The McDonaldization of Society, Ritzer drew on the work of the great German sociologist Max Weber. It was Weber who first pointed out that society was undergoing a process of rationalization, in which a growing number of social institutions were increasingly characterized by efficiency, predictability, calculability, and control over uncertainty, as well as the substitution of technology for human labor. For Weber, no social institution characterized the rationalization process better than bureaucracy, with its rigidly formalized hierarchy of functionaries performing narrowly defined roles according to prescribed rules. ${ }^{3}$ Weber was careful to point out that although rationalized social institutions such as bureaucracies had the advantage of being efficient, if carried to extremes, they could lead to their own form of irrationality, which he termed an "iron cage." The iron cage metaphor referred to Weber 's belief that extremely rationalized institutions could be dehumanizing and stultifying to both those who work in them and those they serve. Ritzer believes that the fast-food industry, exemplified by McDonald's, has replaced bureaucracy as the epitome of the rationalization process. It is the purpose of this study to investigate whether academic libraries have become "McDonaldized," and if so, to what extent. How does the McDonaldization process manifest itself? If academic libraries have become McDonaldized, to what extent is this a positive or negative phenomenon? And finally, are there alternatives to McDonaldization?

Brian Quinn is Social Sciences Librarian at Texas Tech University; e-mail: libaq@lib.ttu.edu. 


\section{McDonaldization and Higher Education}

According to Ritzer, one area of society that is becoming increasingly McDonaldized is higher education. We live in an age of mass higher education, in which many students attend college because they see a college education as a means to a more lucrative career, not because they love learning. Colleges and universities are experiencing growing pressure from the public and state legislatures to control costs and maximize efficiency. These changes in the governmental and economic environment have contributed to increasing the management role of university administrators and lessening the independence of faculty, including library faculty. Increased competition for students among many academic institutions has resulted in a new emphasis in academia on marketing, quality service, and treating students as consumers or even "customers."

This adoption of business management and marketing principles by academia has placed faculty under growing pressure to be more accountable and more productive, to maintain longer office hours, to assume greater teaching loads, to publish more, to compete for grants, and to submit to posttenure review. The importation of business concepts into academia generally, and the academic library in particular, has resulted in the growing popularity of mission and vision statements, service quality concepts, and an interest in leadership among library administrators. The prevalence and standardization of policies, procedures, strategies, goals, and deadlines, along with the specialization of library work into increasingly narrow roles, has contributed to the growth of bureaucratization. In larger libraries, the mushrooming of departments, offices, ranks, titles, reporting lines, and elaborate organizational charts is especially evident.

Students themselves may contribute to the McDonaldization process by approaching the university and the library as consumers would. They examine cost, quality, and convenience and want to obtain the best-quality "product" for their investment. Like customers at a fast-food restaurant, students want to be able to take classes at convenient times, and the classes themselves must be "palatable" in terms of the way they are taught and the demands they make on the students; otherwise, students tend to drop them. Students want short lines, polite and efficient personnel, and the flexibility to "have it their way." ${ }^{4}$ For example, many students who approach the library's reference desk no longer merely ask for information but, rather, ask for it in a certain format, often specifying computer instead of paper sources. Determining which format would best provide information was once the professional prerogative of the librarian. Now, however, many students find computers faster and easier to use than paper sources and may insist on obtaining their information in a convenient form. The quality of the information becomes secondary. In turn, librarians must acquiesce by providing the "Information Happy Meals" the students are seeking in order to guarantee "customer satisfaction."

The growing commercialism in higher education contributes to McDonaldization in other ways. To ensure a continued customer base and keep students from dropping out, many negative aspects of the library research experience are being reexamined. Accustomed to a higher level of service from public and school librarians, many new students may demand that the librarian find information for them rather than be shown by the librarian how to find it themselves. Many academic librarians have a goal to help create independent lifelong learners, but some students regard library research as being too much like work. The result is a "dumbing down" of reference services in order to placate the student. ${ }^{5}$ In the McDonaldized library, "the customer is king," which essentially means giving students what they want rather than what they need. 


\section{Characteristics of McDonaldization}

In his analysis of the McDonaldization phenomenon, Ritzer said that the rationalization process that lies at the heart of McDonaldization has four key characteristics: efficiency, predictability, calculability, and control. Ritzer believes that these aspects of rationalization now pervade society.

\section{McDonaldization and Efficiency}

Efficiency is the systematic elimination of unnecessary time or effort in the pursuit of an objective. It is exemplified by varied phenomena such as TV dinners, factory farming, the modern supermarket, and housing developments. The interesting question for the purposes of this study is to ask: To what extent can these characteristics be found in academic libraries, and with what effect?

Efficiency in the workplace, according to Ritzer, has its roots in the scientific management principles of F.W. Taylor and in Henry Ford's assembly line. Taylor conducted time-and-motion studies to determine the "best" way for workers to perform a task and, in the process, reduced tasks to narrowly defined, repetitive motions that did not completely use the workers' skills and abilities. Ford's assembly line also reduced work to a series of routine, repetitive tasks in which each worker made a highly specialized contribution to the overall production of the final product. Academic libraries have nothing that quite approaches this level of mechanization of human resources, but the highly rationalized division of labor and narrow specialization found in tiered reference may be thought of as a kind of intellectual assembly line. Although this model of reference service was originally introduced to make better use of the professional expertise of librarians, it may have the unintentional effect of eroding their overall global reference skills and responsiveness by underutilizing their skills in favor of much narrower subject specialization. To the extent that it does this, it may be considered inefficient, maladaptive, and dehumanizing - all qualities Weber warned about when he spoke of the "irrationality of rationality" that could lead to bureaucracy becoming an "iron cage." 6

Taylor's influence also may be found in recent attempts by some academic libraries to quantify certain tasks. Even though his time-and-motion studies were designed for the manufacturing sector, they also can be applied to the service sector. Wright State University, for example, has attempted to create measurable standards of service to ensure that tasks are carried out in a timely way. Users who approach the service desk must be served within three minutes, periodicals must be reshelved within twentyfour hours of receipt, and user suggestions must be responded to in five days. Formal statistics are kept on response times to monitor staff performance. ${ }^{7}$ Interestingly, Burger King has a similar goal to serve customers in three minutes.

The fast-food concept of quick service may have had the effect of raising the expectations of library users. Users seem less content with waiting in line for reference assistance and appear less willing to tolerate delays. Some libraries have responded by giving reference staff pagers so they can be "beeped" if a line forms at the service desk. The use of pagers is another example of how services in academic libraries have become efficiently rationalized.

To achieve even greater efficiency, fast- food restaurants have engineered a system in which the customer performs some of the work. At some fast-food restaurants, customers have to wait in line, bus their own trays, fill their own drinks, add their own condiments, and dispose of their own trash when they have finished. The same efficiency is making its way into academic libraries. In some instances, users are being asked to do more themselves. Not only are they expected to do their own computerized searching, but also their own photocopying and interlibrary loan (ILL) requests. 
Some libraries expect users to conduct their own "selfguided" library tours, and 3M has introduced a system that allows users to check out their own books. An ad for the new 3M SelfCheck System has a headline that reads: "They pump their own gas. They withdraw their own cash. They even buy their own stocks. Aren't your patrons ready to check out their own materials?" 8

Ritzer used the "just-in-time" auto parts inventory system developed by the Japanese as an example of an improvement in efficiency over the American "just-in-case" system. In the American system, parts had to be stored until they were needed, greatly increasing storage costs. The Japanese system enabled parts to be delivered to the assembly line, just as they were needed. Academic libraries have begun to use a similarly efficient approach to collection development. Rather than attempting to amass vast collections of books and journals, the libraries are relying more on ILL and document delivery services to supply resources on an as-needed basis. ${ }^{9}$ Choosing access over ownership is more cost- efficient for libraries and yet another example of how efficiency has come to pervade academic libraries.

User instruction is another area of academic librarianship that has become highly efficient. Like the McDonaldized package tours to exotic locales mentioned in Ritzer's book, library tours constitute an efficient-albeit a quick and superficial - way of moving people through the library. Like vacation package tours that advertise "ten cities in two weeks," the idea is to expose users to the maximum number of sights in the time allowed. Large research libraries sometimes run multiple tours simultaneously that are carefully coordinated, scripted, and choreographed so as not to run into one another. The tours are run on a tight schedule that allows little time for spontaneity, digression, or surprise.

Other aspects of user instruction have not escaped McDonaldization. Many "oneshot" classes and semester-length courses in library research methods offer standardized, predetermined organization and content. Even evaluation of user instruction has been reduced in some institutions to a standardized checklist of elements that supposedly constitute efficient and effective instruction.

\section{McDonaldization and Calculability}

Calculability is another key characteristic of McDonaldization. Ritzer defined the term calculability as the tendency to measure quality in terms of quantity. In fast- food restaurants, "bigness" is often synonymous with quality, as in "Big Mac or "Quarter Pounder." McDonald's also suggests that quality is reflected in the number of transactions by advertising "Billions Served." Academic libraries manifest a similar preoccupation with size. The Association of Research Libraries (ARL) has created a Membership Criteria Index which consists of a score that is based on the number of volumes held and added, number of current serials, total library expenditures, and total number of professional and support staff reported over a period of years. Candidates for membership must score highly in these categories in order to be eligible for membership. ${ }^{10}$

Many college and research libraries also keep extensive statistics on everything from reference transactions, cataloging statistics, and ILL statistics to circulation statistics, entrance gate statistics, and statistics about online transactions. Often the statistics are compiled for use as evidence of the library's performance to justify requests for budget increases. Even the service quality approach to evaluating academic libraries, which attempts to measure the quality of service provided, makes heavy use of quantification and statistics. Although research on service quality often involves the use of focus groups, it also uses sampling methods and survey research instruments such as SERVQUAL that attempt to quantify quality by measuring user satisfaction. 
Information technology has contributed to the growing emphasis on calculability. OPACS can be used to gather statistics on the number of users who are able to find what they are looking for. The statistics also can be used to determine what category of borrower (faculty, student, public) is using the collection. ${ }^{11}$ In addition, Web-based databases and Web sites can keep track of the number of people who use the resource and when.

\section{McDonaldization and Predictability}

Another key aspect of the rationalization process that is central to McDonaldization is predictability. A rational society is one in which people know what to expect. One of the reasons McDonald's is so popular is that customers know what they are getting - the menu is predictable and the food is consistently mediocre no matter which outlet they visit. Thus, the world of McDonald's is a bland world in which surprise and delight are largely absent.

McDonald's meals are predictable be cause they offer uniform contents and preparation. Similarly, academic libraries offer increasingly predictable content resulting from the widespread use of approval plans to add books and of aggregator packages to add electronic databases and journals to the collection. The collection development process has become more and more standardized, resulting in collection content varying less from one library or type of library to another. ${ }^{12}$ Thus, many small college libraries might be expected to have roughly similar collections, whereas the contents of large research libraries might bear many similarities. Many academic libraries use the same vendors, and although particular subject profiles may vary somewhat, the differences often depend more on a particular library's depth of collecting than on the books themselves. Many titles are chosen from standardized reviewing sources such as Choice and ARBA, so that most of the unique and unusual content in a library's collection is relegated to "special collections."

Just as paper collections have come to exhibit more similarities than differences, the advent of aggregator packages has resulted in a growing similarity of electronic collection content. Many of these packages are negotiated through library consortia that do not allow their member libraries much flexibility in terms of customizing content. Aggregators themselves do not always allow libraries to select which titles they want, so the library may be faced with a "take it or leave it" proposition.

Not only have many of the resources found in academic libraries become increasingly predictable, so have the services. The kind of service one receives at the reference desk, for example, has become fairly predictable. Most professional librarians working at the reference desk receive similar training in both library school and orientation after they arrive at the library. Student assistants working at the desk also are generally given standardized training. Sample questions and role-playing responses are designed to encourage predictable responses. ${ }^{13}$ Similar training is given to all McDonald's counterpeople so that they will behave in a predictable manner when interacting with customers. The same kind of training is given at other library service desks such as circulation and reserve, resulting is a high degree of uniformity at major service points throughout the library. In addition, the processes and procedures by which materials are requested and delivered such as ILL, document delivery services, and searching for and recalling items are all standardized and require completion of standardized forms by users.

Many academic libraries even offer users a predictable culture. Just as McDonald's predictably features a bright, cheerful, fun, carnival-like atmosphere symbolized by the clown figure Ronald McDonald and, more recently, specialized play areas with rides, slides, and chutes designed to attract families with children, many academic 
libraries have a predictable ambiance. A number of academic libraries now offer "art in the library" programs. Many of these programs have a similar goal: to position the library as not just a research institution, but also a cultural center on campus. Art in the library programs typically feature a series of concerts, readings, performances, screenings, or exhibits that often bear more similarities than differences to one another.

\section{McDonaldization and Control}

The fourth and final aspect of McDonaldization is control. People represent the most unpredictable aspect of rationalized, bureaucratized systems, so it is people that McDonaldized organizations attempt to control. In academic libraries, these people include both librarians and library users themselves, the students and faculty. Ritzer believes that the main way McDonaldized organizations control people is through technology, broadly defined. He believes that bureaucracy itself may be thought of as one form of technology.

Academic librarians are typically subject to an elaborate, formalized system of bureaucratic accountability that serves as a form of control. Each librarian's performance is carefully documented by various means, such as systematized monthly reports to supervisors, annual or semiannual evaluations recorded on standardized forms that must be signed by both librarian and supervisor, less frequent, but periodic, review by promotion and tenure committees, and, more recently, posttenure review committees. Typically, librarians must pursue both personal and departmental goals that have been screened and approved by administrators. Often these goals are accompanied by mandatory time frames specifying when they will be attained and by what means. Librarians who do not meet expectations are likely to be "written up" by their supervisor and receive a negative evaluation. Supervisors faced with a librarian who presents them with performance problems are likely to create a "paper trail" of detailed notes and observations about the employee's behavior, in an attempt to document a pattern of unsatisfactory performance.

According to Ritzer, technology is easier to control than humans, so the ultimate goal of McDonaldization is to replace humans with technology. As an example, he mentioned the mechanized assembly line used to produce food and drinks at McDonald's. The author used physicians as another example and believes their professional judgment is gradually being eroded by, on the one hand, sophisticated computerized diagnostic systems that analyze medical test results and, on the other, do-it-yourself diagnostic kits for conditions such as diabetes and pregnancy. Analogous developments may be occurring in academic libraries. In technical services, the use of online bibliographic utilities such as OCLC has eliminated the need for much professional judgment in cataloging. In public services, the development of expert systems in reference, such as the University of Houston's Reference Expert, may lessen the need for professional reference assistance. Reference Expert is a computerized system that recommends reference sources for answering some types of questions. ${ }^{14}$

In addition to controlling employees through bureaucratic supervision and fastfood technology, McDonaldization also represents an effort to control customers. Restaurant customers are expected to gather their own napkins and utensils, add their own condiments, serve themselves, and clean up after themselves. In some fast-food restaurants, such as Burger King, customers also are expected to fill their own drinks. Moreover, some fast-food restaurants have even designed the seating to be Spartan and uncomfortable, featuring stools with no backs, so that customers are discouraged from lingering, thus enabling tables to turn over quicker. Academic libraries attempt to control their users in similar ways, for example, by posting signs that limit the use of computer terminals to a specified time period or limiting computers to certain types 
of use, often exclusively for research purposes with e-mail use forbidden. Some libraries also use uncomfortable seating or remove chairs from terminals altogether, so that users must stand to conduct a search and are less likely to monopolize a terminal for an extended time period.

\section{Alternatives to McDonaldization: Humor Rooms, Joy Clubs, and Skunk Works}

The overall portrait that emerges from the preceding analysis is that many academic libraries are highly efficient, predictable, and controlled environments. Although there are obvious advantages to maintaining a well-organized and efficient work environment, there also are disadvantages. A highly rationalized library can produce irrationalities for the librarians who work there in the form of dehumanizing, disenchanting work that lacks excitement and challenge. Bureaucratic management systems that exclude librarians from decision making and do not empower them to perform their job the way they see fit may create a McDonaldized environment of disaffected individuals incapable of initiative and vision. A hyperrationalized, ultraefficient environment can create problems for users as well. Some research libraries now offer access to so many databases that users have difficulty choosing and locating the right one. To accommodate the greatest number of users, some OPAC systems are programmed to terminate a session after only a few minutes if no commands are entered, forcing some users to start a new session again. Users who do not understand the difference between an information desk and a reference desk may wind up getting inadequate answers to their questions because they approached the wrong tier.

The kind of bureaucratic, McDonaldized environment that seems characteristic of many academic libraries has been criticized for creating so many levels of administrative approval that it is difficult to accomplish much that is innovative. Boldness, experimentation, and organizational responsiveness all suffer as a result. In a time of rapid change, McDonaldized libraries are slow to respond, simplistic, and shortsighted because they are unable to engage the heads and hearts of their employees and are out of touch with the real needs of their users. ${ }^{15}$

At the same time, organizations in the private sector are discovering that their ability to survive depends on imaginative responses to rapid change. Companies that fail to create new products and services are unable to survive in the face of more creative competitors. New alternative models of organization rely less on rationalization than on fostering creativity and intuition among employees to solve problems. Engendering creativity among librarians may thus constitute an antidote to the bureaucratic excesses of McDonaldization. The role of administration becomes one of promoting an innovative environment by encouraging new ideas and initiatives. Major companies such as Frito-Lay and Dupont now offer creativity-training programs to their employees. The idea is to teach staff to view problems from completely different perspectives in order to help arrive at fresh solutions. Creativity enhancement techniques are taught, such as brainstorming and recording one's dreams. At Boeing, employees are taught the use of mind mapping, in which a central idea is drawn on paper and new ideas are than added on stems branching out from the original concept. ${ }^{16}$ Dupont sets aside time for "creativity social hours," in which creative role models talk about how they use the creative process. ${ }^{17}$ As successful as these programs have been, some management faculty feel that stimulating creativity is not as critical as creating an environment that does not extinguish creativity through hierarchy, closed- mindedness, skepticism, and criticism. One highly creative and successful company, Virgin Atlantic Airways, has no organizational flowchart, traditional company hierarchy, or formal meetings. ${ }^{18}$

If organizational structure and culture play a pivotal role in how creative a library is, how can these be utilized? One approach is to encourage risk taking and experimen- 
tation by making them acceptable and tolerating mistakes and failures. Encouraging employees to question even the most basic assumptions of the library by asking the kind of questions a child might ask, such as "What is a library?" is another means. ${ }^{19}$ At The Body Shop, a personal care products company with hundreds of retail outlets, a creative culture is encouraged by urging employees to constantly question what it is they are doing and how they are doing it. Equally important is the fact that when staff have ideas they can contact DODGI (Department of Damned Good Ideas), where management will listen and take them seriously. ${ }^{20}$

Kodak has helped to create a risk-taking culture by taking itself lightly, through the creation of a humor room. The humor room is stacked with toys, games, and funny videos that help employees to "lighten up" and generate novel, unconventional ideas. It contains a resource library of books, audiocassettes, and cartoons by leading humorists. The walls are hung with photos of Groucho Marx and Charlie Chaplin, and the room contains meeting areas that allow groups to hold meetings there. There is also a high-tech area equipped with personal computers that run creative problem-solving and idea-generation software, which employees can use to gain novel perspectives on work problems. ${ }^{21}$ Hallmark has its own innovation facility called Carney Farm, a complex of studios near its Kansas City headquarters where employees can attend workshops, hear lunchtime speakers, and engage in arts and crafts activities, all designed to stimulate creativity and ideation. ${ }^{22}$ Similarly, AT\&T has created Idea Verse, a place designed to inspire creative activity that features avantgarde decor such as purple walls, beanbag chairs, and wildly painted floors and ceilings. Like Kodak's humor room, employees can drop in to browse the library or watch videos. But Idea Verse also offers "Ideaversity," a collection of courses designed to help staff generate fresh solutions to company problems by jarring them out of conventional thinking patterns and routines. ${ }^{23}$ DuPont also has established a Center for Creativity and Innovation that uses creativity techniques to educate employees. ${ }^{24}$

Just as Kodak has a humor room to stimulate employee creativity, another innovative and successful company, Ben and Jerry's Ice Cream, has created a "joy gang" to help reduce routine and increase enthusiasm among staff. The joy gang challenges established company routines by sponsoring special events at work once each month. One such event was Elvis Day, in which employees participated in an Elvis look-alike contest. The gang consists of six volunteers from different departments that periodically engage in unusual and eccentric activities, such as preparing a full-course Italian dinner for the night shift workers. ${ }^{25}$ They also distribute "joy grants" of up to $\$ 500$ to work units that come up with the most creative ideas. The joy gang can be seen as a creative approach to promoting creativity and spontaneity within an organization.

Southwest Airlines has a strongly anti- McDonaldized company culture in which creativity, breaking the rules, spontaneity, and humor are emphasized. Employees are given the flexibility to express their personalities as they see fit and frequently will relate to customers and colleagues in a playful, irreverent way. One flight attendant has been known to put rubber cockroaches in customers' drinks when they become difficult. Subsequently, she was awarded SWA's President's Award for her outstanding performance, which is considered one of the highest awards an employee can receive. One of the reasons Southwest is so successful is that customers love being treated like real people rather than "customers." Think of the implications this may have for the growing trend among academic libraries to characterize their users as customers. Southwest's decidedly unbureaucratic culture is reinforced by the SWA Culture Committee, which consists of sixty-six employees from various departments as well as customers. The committee is a creative management group that generates ideas to 
promote and sustain a cultural emphasis on employees doing things that are out of the ordinary and extending themselves beyond the call of duty. ${ }^{26}$ The committee has helped the airline maintain its iconoclastic culture despite the company's rapid growth and expanding workforce.

Large, bureaucratic, McDonaldized libraries also may learn much from the experience of large high-tech companies that struggle to compete with smaller, more nimble companies. Some of these firms have taken to forming "skunk works," a small group of five to seven employees who work on formulating creative solutions to company problems. Companies such as Lockheed, IBM, and Dupont have all used skunk works successfully. To be effective, a skunk works must have the support of management and must be insulated from the company's day-to-day operations. The skunk works needs to be protected because its culture is antithetical to that of a McDonaldized bureaucracy. The inflexible requirements of a bureaucratized management structure, with its constant demands for reports, memos, and meetings, would undermine the focus and flexibility needed for a skunk works to be effective. McDonaldized organizations frequently have multiple levels of administration as well as administrators who may engage in petty office politics. They form fiefdoms that have numerous rules and policies associated with them that can end up creating considerable red tape for anyone who is trying to accomplish something that is not "standard procedure" or who is unwilling to "go through channels." By avoiding bureaucracy, skunk works members can be more creative and achieve results faster. ${ }^{27}$

Ideally, the skunk works should consist of the most creative and visionary librarians available, perhaps with an entrepreneurial bent as well. Participants can be recruited through voluntary sign- up to increase commitment. Rather than having a leader appointed for the group, the leader should be allowed to emerge naturally so that the group seems less hierarchical. Group members may need to be rotated periodically to avoid burnout. They should be allowed to go directly to the library's top management with ideas that they believe are important and thus bypass layers of entrenched middle managers who might be tempted to dismiss an idea with the all-too-common epithet "that will never work here." 28

\section{Recruiting Un-McDonaldized Librarians}

Creating an un-McDonaldized culture in the library is much easier when the library has un-McDonaldized librarians. These individuals can be actively recruited by going beyond the standard requirement of an ALA-accredited MLS, an affinity for technology, knowledge of a foreign language, or other conventional criteria. Asking a candidate for evidence of creativity, whether in terms of unusual projects undertaken or a bold vision of the future, could be one way to gauge a person's potential. Perhaps a key question might be, How much of a risk taker is the person ${ }^{29}$ A librarian who has taken some intelligent risks, and learned from failures, might be a better fit for an un- McDonaldized library than one who has a flawless, but colorless, career based on always playing it safe. Another way to build an un-McDonaldized culture is to create a system of evaluation and incentives that rewards librarians for innovation and encourages those who refuse to be venturesome to perform better. It helps to reward librarians based on the risks they take, rather than on just the results. Rewards do not necessarily have to take the form of increased salary; they also can take the form of more time free of regular responsibilities to think creatively. Hewlett Packard, Texas Instruments, and 3M allow their most creative people to spend a percentage of their time on the job coming up with new ideas and solutions. ${ }^{30}$ TRW and Apple award employees free time in the form of "fellowships" that consist of larger blocks of time along with freedom from corporate interference. ${ }^{31}$ 
Although these ideas may seem novel to the typical McDonaldized library, some companies have gone even further. Hewlett-Packard has awarded "medals of defiance" to employees who defy top management to pursue projects they believe in that later turn out to be successful. Providing this kind of organizational recognition to maverick employees can be an effective way to cut through the morass of politics and bureaucracy that often characterizes a McDonaldized culture and serves to stifle fresh ideas. ${ }^{32}$ To eliminate "yes-men," Scandinavian Airlines has instituted a training program for new employees that is designed to "flatten the pyramid" by encouraging them to behave assertively with management and tell managers how to improve company operations whether they wish to hear it or not. The idea is to prevent subordinates from allowing bosses to make decisions or institute policies that the employees know will have a negative effect on operations. One company, Royal Dutch Shell Group, has even gone so far as to sanction designated devil's advocate groups to actively promote alternative strategic plans designed to help the company cope with any scenario. ${ }^{33}$

\section{Creativity Audits and the Tyranny of Teams}

McDonaldized libraries also might consider conducting a creativity audit. This involves identifying those individuals within the library who seem to come up with interesting ideas on a regular basis. These librarians should be sheltered from criticism and rewarded whenever they produce valuable insights. Moreover, they should be given special assignments and projects that address important organizational issues so they will be challenged and not feel underutilized. ${ }^{34}$ In addition, they might be appointed discussion leaders to help stimulate the exchange of ideas among colleagues. Creative individuals should be given direct access to top-level administrators in order to prevent supervisory personnel at various levels from undermining ideas.

It also might be helpful to avoid the tyranny of teams, which sometimes may interfere with the development of creativity. Although the use of teams has become popular in some academic libraries, making creativity a team project may not necessarily result in better ideas. Many individuals may not respond well to group brainstorming for fear of saying something foolish in front of others or their supervisor. Librarians who are individualists may need privacy and a degree of isolation in order to be their most original. Management should not try to force all librarians to be "team players" when it comes to the creative process and should allow some librarians to venture off on their own if that is how they work best.

\section{A Career Path for Creatives}

To advance in their career, many of the most creative academic librarians have little choice but to assume supervisory roles at some point and move into management. This usually involves a lot of administrative paperwork as well as responsibility for overseeing the work of others, tasks the individual may not be particularly interested in or suited for. The alternative would be for the librarian to stay in his or her present position with little possibility for advancement, which could potentially create a morale problem. Companies such as Microsoft and 3M avoid this problem by creating dualcareer paths, one administrative and the other technical and professional. Each path offers comparable positions in terms of pay, benefits, and status. A similar structure would allow the library to retain its most creative people and yet allow them to develop and stay engaged by utilizing their creative ability as librarians. ${ }^{35}$

\section{Information Technology and Creativity}

Although Ritzer believes McDonald's uses technology as a means of controlling people with the eventual aim of replacing them altogether, the relationship between technol- 
ogy and McDonaldization is more complex. Although technology may have a negative effect on employees and help contribute to a mechanized, rationalized, McDonaldized environment, it also may have the opposite effect and become a tool for creativity in the library. Much depends on how technology is used.

The McDonaldized library, with its bureaucratic hierarchy of superiors and subordinates organized along narrow and rigid reporting lines, is designed to restrict and control information. Top administrators tend to have a monopoly on information and know about things before anyone else in the library. Information can be withheld from subordinates as a way of controlling them. One advantage of information technology is that it tends to open up channels of communication so that simultaneous dissemination of information, in which managers are informed at the same time as subordinates, becomes technically possible. ${ }^{36}$

The role of many middle managers in McDonaldized libraries has been one of information gatherer and disseminator, someone who serves as both a link in the communication chain and a gatekeeper. The middle manager interprets the wishes of top management to those below and conveys information about the rank and file to those above. Yet, middle managers often serve a countercreative function in the library by telling creative subordinates that their ideas will never be accepted by top administrators and thus blocking off access. Thus, controlling information becomes a way of maintaining or enhancing the middle manager's power. ${ }^{37}$ Information technology may threaten this power by making it easier for subordinates to bypass middle managers and communicate ideas directly to the top.

Information technology can contribute to creativity in other ways. It can be used to generate new ideas; to facilitate association between disparate ideas, as in the case of hypertext; or to explore ideas informally using e-mail or chat systems. ${ }^{38}$ Spreadsheets allow for the creative manipulation of numbers. Simulation packages make it possible for complex organizational processes to be modeled, making it possible for people to experiment with ideas without engendering real- world consequences. In addition, there are software packages that simulate or facilitate creative problem-solving techniques such as brainstorming and morphological analysis, which allows users to conceptualize the dimensions of a product and then derive attributes that can be managed and sorted to create new product ideas. ${ }^{39}$

Another way that information technology can enhance creativity is through electronic meeting systems. Although still commonly used in academic libraries, many companies have abandoned brainstorming as a way of generating creative ideas in favor of electronic meeting systems. One reason is that brainstorming is a group process that tends to be personality driven. Extroverted and aggressive personalities tend to dominate brainstorming sessions, with the result that quieter, more thoughtful participants tend to be overlooked. In addition, many brainstorming participants are afraid of saying something foolish or speaking up in front of supervisors.

Electronic meeting systems allow participants to engage in "brainwriting" rather than brainstorming. Participants sit at networked PCs and type in their ideas, which then appear anonymously on a screen that all can see. These ideas then become springboards for further contributions. People are able to express candid and bold opinions and ideas without fear of ridicule or reprisal. ${ }^{40}$ General Motors uses an electronic meeting system to facilitate brainwriting sessions. It features a bank of networked Macintosh computers arrayed around a conference table. GM has found it an excellent way to reduce group uniformity pressure and perceived threats from managers in attendance. ${ }^{41}$

In addition, there are software programs designed to enhance individual creativity. ${ }^{42}$ Generally, librarians accustomed to working in McDonaldized environments are not accustomed to tapping their creative abilities. Many of these software programs are 
designed to help a user break free of conventional thinking patterns so that he or she can come up with alternative solutions to a problem. One of the best-known programs is Idea Fisher, which uses memory prompts, analogy, metaphor, and free association to help users generate bold ideas. ${ }^{43}$ The user begins by choosing a word, and Idea Fisher then generates thousands of associations and concepts designed to stimulate creative thoughts. As one browses through the associated concepts, ideas can be recorded on an electronic notepad. Idea Fisher also contains a database of thousands of questions that are designed to talk the user through a concept. The program then screens the user 's answers and isolates the most important concepts, which then can be resubmitted to the program to generate additional ideas. ${ }^{44}$ Idea Fisher is only one of many creativity enhancement programs available. Other well-known programs include MindLink, The Innovator, Decision Pad, Idea Generator, Thoughtline, and the Art of Negotiating. Although these packages can be very helpful in the creation of new ideas, it should be emphasized that they are designed to stimulate creativity rather than simulate it. They are not meant to be a substitute for the human thinking process but, instead, are meant to complement it. ${ }^{45}$

\section{Conclusion}

Using the criteria that Ritzer has suggested are most characteristic of McDonaldization-efficiency, predictability, calculability, and control, it appears that in many ways academic libraries can be characterized as McDonaldized environments. Large research libraries in particular tend to be complex institutions that are organized and managed along bureaucratic lines. Added to this highly bureaucratic environment is a more recent trend toward using business and marketing principles to manage higher education, which has affected the way that academic libraries are being managed. Library administrators are being encouraged to think of students and faculty as "customers" who must be given high-quality service in order to deter them from taking their business to a competing institution. ${ }^{46}$

The McDonaldization process has resulted in the increasing standardization of products and services, so that academic libraries are becoming more similar to one another. Ironically, at a time when college and university libraries are feeling the pressures of the marketplace and an increasing commercial ethos on their operations, many businesses are moving away from the bureaucratic, McDonaldized model of management that characterizes academic libraries. Companies have discovered that to survive in an intensely competitive business environment, it is increasingly necessary to cultivate creativity among employees. The more creative a company's environment, the more likely it will generate new products and services needed to differentiate itself from its competitors in the marketplace. ${ }^{47}$ Firms in the private sector thus regard building a culture of creativity as essential to survival, rather than a fleeting management fad.

As the field of higher education becomes more competitive and adopts more of a marketplace emphasis, academic libraries will likely experience additional pressure to come up with new products and services to keep users satisfied.$^{48}$ Like their businessworld counterparts, they may need to become less McDonaldized and more creative. If they do not, more innovative competitors may take the initiative and create new and better ways to meet user needs.

This study has tried to suggest some of the ways that companies are becoming less McDonaldized and more creative. It does not seem unreasonable to suggest that academic libraries could take a cue from some of these firms and try to adopt some of their ideas. Is it impossible to introduce a humor room, a joy gang, or a skunk works into the academic library environment? At the very least, reorganizing for innovation by experimenting with some of these alternatives might make the work of librarians 
more interesting and engaging. ${ }^{49}$ Perhaps in the process, academic libraries may come up with their own versions of creativity enhancement programs and strategies that seem to be most effective or appropriate.

More research is needed on the various means that companies are using to become more creative. It also would help to investigate the kinds of results these companies have had with their undertakings. On the library side, libraries need to experiment more with creativity enhancement techniques and initiatives, and report their results in the library literature. The eventual goal would be to make libraries less rigid, less bureaucratized, and less imitative of each other; in other words, less McDonaldized and more like laboratories for experimentation whose most important results are shared and built on.

\section{Notes}

1. George Ritzer, The McDonaldization of Society: An Investigation into the Changing Character of Contemporary Social Life (Thousand Oaks, Calif.: Pine Forge Pr., 1993).

2. Mark Alfino, John S. Caputo, and Robin Wynword, eds. McDonaldization Revisited: Critical Essays on Consumer Culture (Westport, Conn.: Praeger, 1998).

3. Max Weber, Economy and Society (Totawa, N.J.: Bedminster Pr., 1968).

4. George Ritzer, "McUniversity in the Postmodern Society," in The McDonaldization Thesis: Explorations and Extensions, ed. George Ritzer (London: Sage, 1998), 151-162.

5. Katherine Washburn and John F. Thorton, eds. Dumbing Down: Essays on the Strip Mining of American Culture (New York: W.W. Norton, 1996).

6. Thomas W. Segrady, "Rationality and Irrationality: New Directions in Weberian Theory, Critique, and Research," Sociological Spectrum 8 (Jan/Mar. 1988): 616-33.

7. Susan Wehmeyer, Dorothy Auchter, and Arnold Hirshon, "Saying What We Do, and Doing What We Say: Implementing a Customer Service Plan," Journal of Academic Librarianship 22 (May 1996): 173-80.

8. College and Research Libraries News 60 (Mar. 1999): 260.

9. Bruce R. Kingma, "The Economics of Access versus Ownership: The Costs and Benefits of Access to Scholarly Articles via Interlibrary Loan and Journal Subscriptions," Journal of Library Administration 26, nos. 1 / 2 (1998): 145-62.

10. See the ARL Web site at http://www.arl.org/.

11. Peter Hernon and Ellen Altman, Service Quality in Academic Libraries (Norwood, N.J.: Ablex, 1996).

12. Celia Scher Wagner, "Academic Book Trends-Approval Plans and Library CollectionsDo They All Look Alike?" Against the Grain 10 (Nov. 1998): 73.

13. Janet E. Sheets, "Role-Playing as a Training Tool for Reference Student Assistants," Reference Services Review 26 (spring 1998): 37-41.

14. Shiao-Teng Su and F. Wilfred Lancaster, "Evaluation of Expert Systems in Reference Service Applications," RQ 35 (winter 1995): 219-28.

15. Gifford Pinchot and Elizabeth Pinchot, The End of Bureaucracy and the Rise of the Intelligent Organization (San Francisco: Berrett-Koehler, 1993).

16. "Can Imagination Be Taught?" Supervision 52 (Nov. 1991): 5-26.

17. David Tanner, "Innovative and Creative Change," Executive Excellence 9 (June 1992): 15-16.

18. David Sheff, “The Interview: Richard Branson," Forbes (Feb. 24, 1997): 94-102.

19. Shari Caudron, "Corporate Creativity Comes of Age," Training and Development 52 (May 1998): 50-55.

20. Lisa K. Gundry, Charles W. Prather, and Jill R. Kickul, "Building the Creative Organization," Organizational Dynamics 22 (spring 1994): 22-37. 63-68.

21. Shari Caudron, "Humor Is Healthy in the Workplace," Personnel Journal 71 (June 1992)

22. Gail Dutton, "Enhancing Creativity," Management Review 85 (Nov. 1996): 44-46. $32-40$.

23. Bob Filipczak, "It Takes All Kinds: Creativity in the Work Force," Training 34 (May 1997):

24. David Tanner, "Applying Creative Thinking Techniques to Everyday Problems," Journal of Consumer Marketing 9 (fall 1992): 23-28.

25. Jennifer L. Laabs, "Ben \& Jerry's Caring Capitalism," Personnel Journal 71 (Nov. 1992): 50-57. 26. Brenda Paik Sunoo, "How Fun Flies at Southwest Airlines," Personnel Journal 74 (June 
1995): 62-73.

27. Peter Gwynne, "Skunk Works: 1990's-Style," Research-Technology Management 39 (July/ Aug. 1997): 38-41.

28. Arthur W. Single and William M. Spurgeon, "Creativity and Commercializing Innovation inside a Skunk Works," Research-Technology Management 39 (Jan./Feb. 1996): 38-41.

29. Tom Peters, "Walk on the Wild Side," Incentive 167 (June 1993): 43.

30. Thomas Kiely, "The Idea Makers," Technology Review 96 (Jan. 1993): 32-40.

31. Ashok K. Gupta and Arvind Singhal, "Managing Human Resources for Innovation and Creativity," Research-Technology Management 36 (May/June 1993): 41-48.

32. Charlan Jeanne Nemeth, "Managing Innovation: When Less is More," California Management Review 40 (fall 1997): 59-74.

33. Frank Sommerfield, "Paying the Troops to Buck the System," Business Month 135 (May 1990): 77-79.

34. Michael Syrett, "Nurturing Ideas Pays Dividends," Asian Business 32 (Feb. 1996): 20-23.

35. Shari Caudron, "Motivating Creative Employees Calls for New Strategies," Personnel Journal 73 (May 1994): 103-6.

36. Rosabeth Moss Kanter, "Can Giants Dance in Cyberspace?" Forbes (Dec. 2, 1996): 247-48.

37. David Jackson and John Humble, "Middle Managers: New Purpose, New Directions,"

Journal of Management Development 13, no. 3 (1994): 15-21.

38. Omar E. M. Khalil, "Innovative Work Environments: The Role of Information Technology and Systems," S.A.M. Advanced Management Journal 61 (summer 1996): 32-36.

39. Tony Proctor, "Computers and Creative Problem Solving," Management Research News 16 (Sept./Oct. 1993): 21-26.

40. Michael Finley, "Meeting Tools Organize Brainstorming Process," Public Relations Journal 49 (Mar. 1993): 40-43.

41. Kiely, "The Idea Makers," 34.

42. Brenda Massetti, "An Empirical Examination of the Value of Creativity Support Systems on Idea Generation," MIS Quarterly 20 (Mar. 1996): 83-97.

43. John Thackray, "That Vital Spark," Management Today (July 1995): 56-58.

44. R. A. Proctor, "Can Computers Simulate Managerial Creativity?" Leadership and Organization Development Journal 12, no. 4 (1991): 13-16.

45. Kyle Heger, "Whiz ...Bang ...Eureka! The Automation of Creativity," Communication World 8 (Nov. 1991): 18-21.

46. Annette Davies and Ian Kirkpatrick, "Face to Face with the 'Sovereign Consumer': Service Quality and the Changing Role of Professional Academic Librarians," Sociological Review 43 (Nov. 1995): 782-807. $9-23$.

47. Constantinos Markides, "Strategic Innovation," Sloan Management Review 38 (spring 1997):

48. Martin Parker and David Jary, "The McUniversity: Organization, Management, and Academic Subjectivity," Organization: The Interdisciplinary Journal of Organization, Theory, and Society 2 (1995): 1-20.

49. Tim Handyside and Janice Light, "An Experiment in Organization for Innovation," International Journal of Technology Management 15, nos. 1 / 2 (1998): 160-72. 